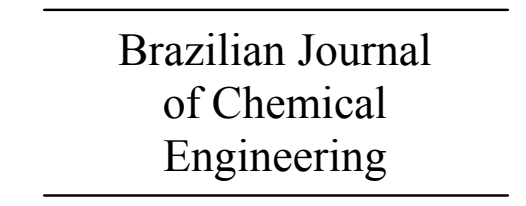

ISSN 0104-6632

Printed in Brazil

www.abeq.org.br/bjche

Vol. 30, No. 04, pp. 793 - 799, October - December, 2013

\title{
ANALYTICAL APPROACH BASED ON A MATHEMATICAL MODEL OF AN AIR DEHUMIDIFICATION PROCESS
}

\author{
D. Babakhani \\ Young Researchers and Elite Club, Farahan Branch, Islamic Azad University, Farahan, Iran. \\ Phone/Fax: (+ 98) 0862-6622518; Postal Code: 39531. \\ E-mail: engbabakhani@gmail.com
}

(Submitted: November 26, 2011 ; Revised: December 9, 2012 ; Accepted: December 26, 2012)

\begin{abstract}
In this paper we developed an analytical solution for a mathematical model of an air dehumidification process. This solution has good accuracy when compared with reliable experimental data available in the literature. The present study was confined to the cases with the mass flow rate of desiccant solution being much greater than the minimum required by the equilibrium calculation, so that the changes in the concentration and the flow rate are relatively small. Validation of this assumption has been performed by HYSYS software version 3.2. The influence of the Lewis number (Le) on the analytical results was considered. As shown in the current study, we obtain better results with Le=1.1 compared with Le=1. The benefits of the present solution are its simplicity and easy application for the simulation of air dehumidification.

Keywords: Dehumidification; Heat and mass transfer; HYSYS.
\end{abstract}

\section{INTRODUCTION}

Liquid desiccant cooling systems driven by solar energy or other heat sources have emerged as a potential alternative or as a supplement to conventional vapor compression (V-C) systems for cooling and air conditioning. Dehumidification and regeneration are the key processes. Internally cooled or heated liquid desiccant-air contact units have been widely studied for their potential applications in effective air dehumidification, desiccant regeneration or high capacity energy storage systems (Scalabrin and Scaltriti, 1990; Hellmann and Grossman, 1995a; Hellmann and Grossman, 1995b; Kessling et al., 1998a; Kessling et al., 1998b). The heat and mass transfer process in the packed dehumidifier is affected by many parameters, such as the relative flow direction of the air to the desiccant, the type and material of the packing and the inlet parameters of the air and the desiccant. The dehumidifier is one of the most important components in the liquid-desiccant system, whose heat and mass transfer performances directly affect the whole system performance. In the dehumidifier, combined heat and mass transfer processes occur synchronously, and the heat transfer and mass transfer processes influence each other. Recently, the field of liquid desiccant cooling systems has advanced very quickly. Compared with conventional compression refrigeration systems, they have several advantages; they can be driven by low-grade thermal energy and easily realize efficient energy storage that is very suitable for solar energy application (Kessling et al., 1998b). Several mathematical models to predict the heat and mass transfer performance of a packed-type dehumidifier and regenerator are available in the literature. The widely used finite difference model is

*To whom correspondence should be addressed 
based on fundamental equations and gives a numerical solution validated by experimental results (Factor and Grossman, 1980; Fumo and Goswami, 2002; Gandhidasan, 2004). For optimum design of desiccant cooling systems and annual energy performance analyses, it is most desirable to obtain an analytical solution to the general differential equations. For example, in Hellmann and Grossman's model (1995), the solution film heat and mass transfer resistances were introduced in their model equations. The outer surface of the tube banks was assumed to be uniformly wetted and the Lewis factor was assumed to be equal to unity. Chengqin et al. (2006) rearranged the general differential equations and an analytical solution was developed. For the four possible flow arrangements of the parallel/counter flow configurations and three types of commonly used liquid desiccant solutions, the results of analytical solutions were compared with those of numerical integration over a wide range of operating conditions and the agreement was found to be quite satisfactory. Chen et al. (2006) presented an integrated analytical solution of adiabatic heat and mass transfer in packed-type liquid desiccant equipment based on proposed mathematical models in both parallel-flow and counterflow configurations. In the derivation process, the desiccant concentration at the inlet and outlet of the absorber was assumed to be constant. Babakhani (2009) presented an analytical solution of simultaneous heat and mass transfer processes in a packed bed liquid desiccant dehumidifier/regenerator. Various dimensionless parameters and reliable assumptions were used in order to develop this solution. Longo and Gasparella (2005) presented the experimental tests and the theoretical analysis of the chemical dehumidification of air by a liquid desiccant and desiccant regeneration in an absorption/desorption column with random packing. Liu et al. (2007) presented analytical solutions of the air and desiccant parameters that affect the heat and mass transfer performance. Many researchers have developed mathematical models of the coupled heat and mass transfer processes in the dehumidifier or regenerator, and most of the models were solved numerically. Compared with numerical solutions, analytical solutions have advantages in analyzing the parameters that affect the heat and mass transfer performance. For this purpose, in the current study, an analytical approach based on the Laplace method for the mathematical model of the coupled heat and mass transfer process in air dehumidification has been presented. The analytical results have been compared with experimental data (2004) and show good agreement.

\section{MATHEMATICAL MODEL AND ANALYTICAL APPROACH}

As found in many conventional practices (Saman and Alizadeh, 2001; Jain et al., 2000; Khan and Martinez, 1998), the following assumptions were adopted in the present study:

1) Zero wall, air thermal and moisture diffusivity in the flow directions;

2) No heat transfer to the surroundings;

3) Constant specific heats of air, solution and the fluid, constant heat and mass transfer coefficients, constant surface wettability.

The present study was confined to the cases with the mass flow rate of desiccant solution much greater than the minimum required by the equilibrium calculation so that the changes in the concentration and the flow rate are relatively small. Validation of this assumption has been performed with HYSYS software.

By the principles of energy and mass conservation, a set of differential equations can be obtained for a differential element as shown in Fig. (1) as follows (Treybal, 1980):

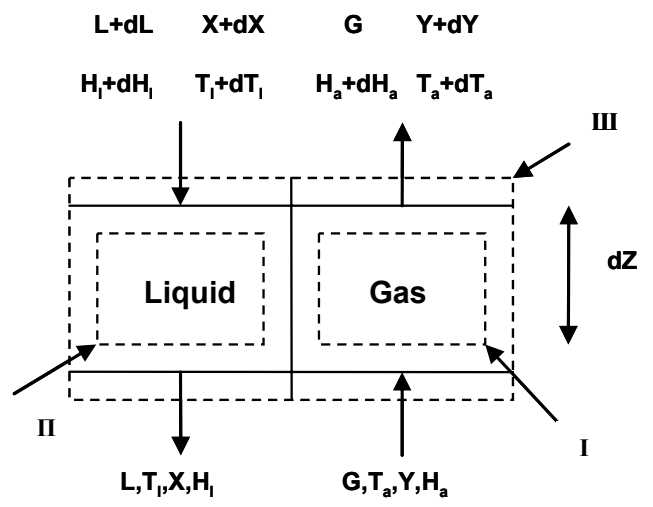

Figure 1: Schematic of the counter-flow heat and mass transfer differential element.

$$
\begin{aligned}
\frac{d Y}{d Z} & =\frac{M_{v} F_{g} a_{w}}{G_{s}} \ln \left(\frac{1+Y}{1+Y_{e}}\right) \\
\frac{d T_{a}}{d Z} & =-\frac{h_{g} a_{p}\left(T_{a}-T_{l}\right)}{G_{s}\left(C_{p, a}+Y C_{p, v}\right)} \\
\frac{d T_{l}}{d Z} & =\frac{G_{s}}{L C_{p, l}}\left(C_{p, m} \frac{d T_{a}}{d Z}+\left[C_{p, v}\left(T_{a}-T_{0}\right)\right.\right. \\
& \left.\left.-C_{p, l}\left(T_{l}-T_{0}\right)+\lambda_{0}\right] \frac{d Y}{d Z}\right)
\end{aligned}
$$


By the use of the dimensionless and dimensional parameters shown in Table 1, we can obtain dimensionless differential equations as follows:

Table 1: Dimensionless and dimensional groups utilized in the derivations.

\begin{tabular}{|l|l|}
\hline NTU $=\frac{M_{v} F_{g} a_{w} Z}{G_{s}}$ & $\begin{array}{l}\text { number of gas phase } \\
\text { mass transfer }\end{array}$ \\
\hline$L e=\frac{h_{g}}{M_{a} C_{p, a} F_{g}}$ & Lewis number \\
\hline$R=\frac{C_{p, a} G_{s}}{C_{p, l} L}$ & $\begin{array}{l}\text { air to solution heat } \\
\text { capacity rate ratio }\end{array}$ \\
\hline$R_{H}=\frac{C_{p, a}}{C_{p, m}}$ & $\begin{array}{l}\text { air to mixture of air and } \\
\text { water vapor specific heat } \\
\text { capacity ratio }\end{array}$ \\
\hline$R_{A}=\frac{a_{p}}{a_{w}}$ & $\begin{array}{l}\text { specific area to effective } \\
\text { interfacial area ratio }\end{array}$ \\
\hline$M=\frac{M_{v}}{M_{a}}$ & $\begin{array}{l}\text { water vapor molar mass } \\
\text { to air molar mass ratio }\end{array}$ \\
\hline $\bar{h}=\frac{h_{f g}}{C_{p}, a}$ & $\begin{array}{l}\text { normalized heat of } \\
\text { absorption }\end{array}$ \\
\hline
\end{tabular}

$\mathrm{d} Y=-m\left(Y-Y_{e}\right) d N T U_{z}$

$d T_{a}=-\operatorname{LeR}_{H} R_{A}\left(T_{a}-T_{l}\right) d N T U_{z}$

$d T_{l}=-R\left\{L e R_{A}\left(T_{a}-T_{l}\right)+\bar{h} m\left(Y-Y_{e}\right)\right\} d N T U_{z}$

In practical dehumidification/regeneration cases, the solution flow rates in packed towers are usually much higher than the minimum flow rate determined from the equilibrium calculation (Chen et al., 2006). Thus, the solution flow rate and concentration changed very little during the overall processes. Therefore, the variation of the equilibrium humidity ratio of the solution will almost certainly be influenced by the change of the solution temperature. Hence, it can be assumed that $Y e$ is linear with $T_{l}$ in the operating temperature range, Eq. (7):

$Y_{e}=a T_{l}+b$

where $a$ and $b$ are both fitted numbers.

With the definitions $\alpha=L e R_{H} R_{A}, \beta=R L e R_{A}$ and $\gamma=R \bar{h} m$, Eqs. (5) and (6) are simplified as follows: $d T_{a}=-\alpha\left(T_{a}-T_{l}\right) d N T U_{z}$

$d T_{l}=-\left(\beta\left(T_{a}-T_{l}\right)+\gamma\left(Y-Y_{e}\right)\right\} d N T U_{z}$

Eqs. (4) to (6) are a coupled equation system and must be solved simultaneously. We can use Laplace transformation methods to solve it.

$s Y(s)-Y(0)=m\left(Y(s)-Y_{e}(s)\right)$

where

$$
\begin{aligned}
Y_{e}(s)=a T_{l}(s) & +\frac{b}{s} \\
s T_{a}(s)-T_{a}(0) & =-\alpha\left(T_{a}(s)-T_{l}(s)\right) \\
s T_{l}(s)-T_{l}(0) & =-\beta\left(T_{a}(s)-T_{l}(s)\right. \\
& -\gamma(Y(s)-Y e(s)))
\end{aligned}
$$

By arranging Eqs. (10), (12) and (13), substituting Eq. (11) yields:

$$
\begin{aligned}
& (s+m) Y(s)+m a T_{l}(s)=Y(0)-\frac{b m}{s} \\
& (s+\alpha) T_{a}(s)-\alpha T_{l}(s)=T_{a}(0) \\
& \gamma Y(s)+\beta T_{a}(s)+(s-\gamma a-\beta) T_{l}(s)= \\
& T_{l}(0)+\frac{\gamma b}{s}
\end{aligned}
$$

The above equations have been solved by the Gauss elimination method as shown below:

$$
O=\left[\begin{array}{ccc|c}
(s+m) & 0 & m a & Y(0)-\frac{b m}{s} \\
0 & (s+\alpha) & -\alpha & T_{a}(0) \\
\gamma & \beta & (s-\gamma a-\beta) & T_{l}(0)+\frac{\gamma b}{s}
\end{array}\right]
$$

The result of the Gaussian procedure is an/a upper/lower triangular matrix as follows:

$O=\left[\begin{array}{ccc|c}(s+m) & 0 & m a & Y(0)-\frac{b m}{s} \\ 0 & (s+\alpha) & -\alpha & T_{a}(0) \\ 0 & 0 & {\left[\frac{\alpha \beta}{s+\alpha}-\frac{\gamma m a}{s+m}+(s-\gamma a-\beta)\right.}\end{array}\right] \mid$ 
where $T_{l}(s), T_{a}(s)$ and $Y(s)$ are given by:

$$
\begin{aligned}
& {\left[\frac{\alpha \beta}{s+\alpha}-\frac{\gamma m a}{s+m}+(s-\gamma a-\beta)\right] T_{l}(s)=T_{l}(0)+\frac{\gamma b}{s}} \\
& (s+\alpha) T_{a}(s)-\alpha T_{l}(s)=T_{a}(0) \\
& (s+m) Y(s)+m a T_{l}(s)=Y(0)-\frac{b m}{s}
\end{aligned}
$$

By solving Eq. (19) for $T_{l}(s)$, the result yields:

$$
T_{l}(s)=\frac{\left(s T_{l}(0)+a_{0}\right)\left(s^{2}+a_{1} S+a_{2}\right)}{s^{4}+a_{3} s^{3}+a_{4} s^{2}+a_{5} S}
$$

where

$$
\begin{aligned}
& a_{0}=\gamma b ; a_{1}=\alpha+m ; a_{2}=\alpha m ; a_{3}=\alpha+m-y a-\beta ; \\
& a_{4}=\gamma a(\alpha+m)-\gamma m a+\alpha \beta+\alpha m-\beta(\alpha+m) a_{5}=-2 \gamma \alpha m a
\end{aligned}
$$

By the use of MAPLE software, we can obtain the Laplace inverse of Eq. (22) as given below:

$$
T_{l}(N T U)=\frac{a_{2}+\sum_{\alpha=\operatorname{Root} \text { of }\left(Z^{3}+a_{3} Z^{2}+a_{4} Z+a_{5}\right)} \frac{e^{-\alpha N T U}\left(-a_{4} a_{2}+a_{1} a_{5}+\alpha^{2}\left(T_{l}(0) a_{5}-a_{2}\right)+\alpha\left(a_{0} a_{5}-a_{3} a_{2}\right)\right.}{3 \alpha^{2}+2 a_{3} \alpha+a_{4}}}{a_{5}}
$$

By substituting Eq. (23) in Eqs. (20) and (21), we can obtain complex parameter expressions for $T_{a}(N T U)$ and $Y(N T U)$.

\section{RESULTS AND DISCUSSION}

In order to use this analytical solution with confidence for predicting the outlet conditions of the processed air, validation is required. Comparisons were made between the predicted values calculated by the analytical solution and experimental values available in the literature. Reliable sets of experimental data using triethylene glycol (TEG) as the liquid desiccant were reported by Zurigat et al. (2004). Their tower had a total height of $0.6 \mathrm{~m}$ with a structured type packing consisting of eight decks with seven plates per deck, resulting in a packing density of $77 \frac{\mathrm{m}^{2}}{\mathrm{~m}^{3}}$ and a packing height of $0.48 \mathrm{~m}$. Desiccant at the required temperature and flow rate was pumped into the top of the tower via the rotameter. The desiccant, flowing countercurrent relative to the humid air flow, was distributed over the packing and absorbed moisture as it came into contact with the humid air. The diluted desiccant flowed by gravity to the catch tank, where it was stored for regeneration. Furthermore, a simulation was performed with HYSYS software. As shown in Fig. (2), the difference between the mass fraction of the liquid desiccant in the inlet and outlet will be decreased upon the increasing the liquid mass flow. Comparison of the experimental results with the results obtained from the present study and the software are given in Figs. (3) to (5).

According to these results, the maximum difference, which is defined as the difference of the mathematical model and the experimental values at the outlet divided by the experimental difference value between the inlet and outlet, for the predicted air humidity, air temperature and liquid temperature are less than $10 \%$. It should also be pointed out for the air dehumidification process that, when $\mathrm{Le}=1$, the predicted outlet conditions are consistently higher than the experimental data, but when $\mathrm{Le}=1.1$, the predicted outlet conditions are in better agreement with the experimental results, as shown in Figures (3) to (5). 


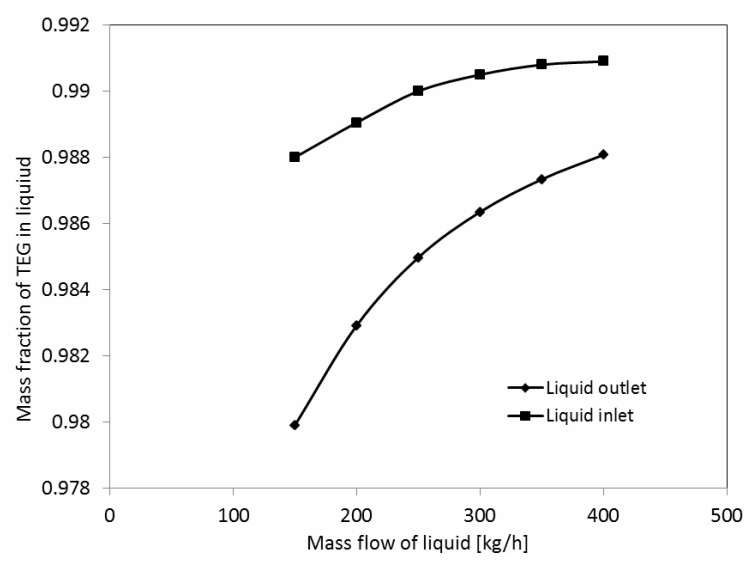

Figure 2: Inlet and outlet concentration changes of the desiccant with regard to the liquid mass flow.

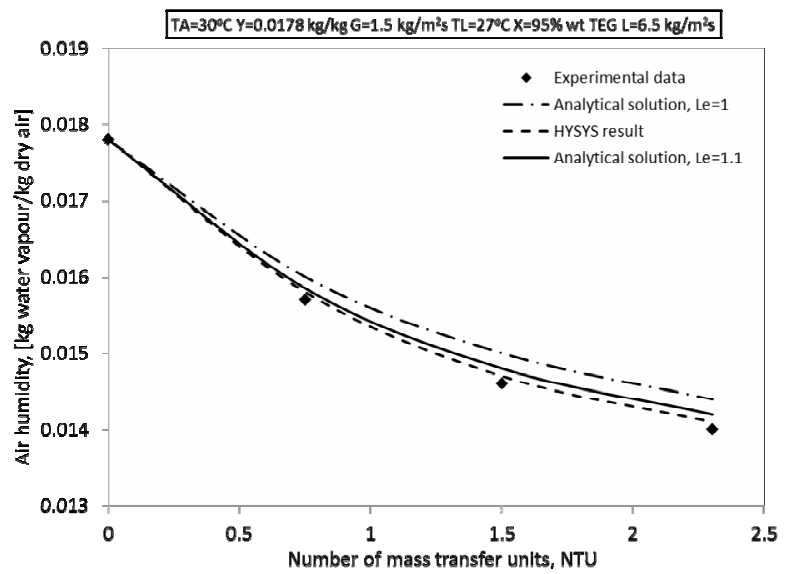

Figure 3: Comparison between the analytical solutions (with $\mathrm{Le}=1 \& \mathrm{Le}=1.1$ ), the experimental data of Zurigat et al. (2004) and HYSYS results for the changes of air humidity in the dehumidifier.

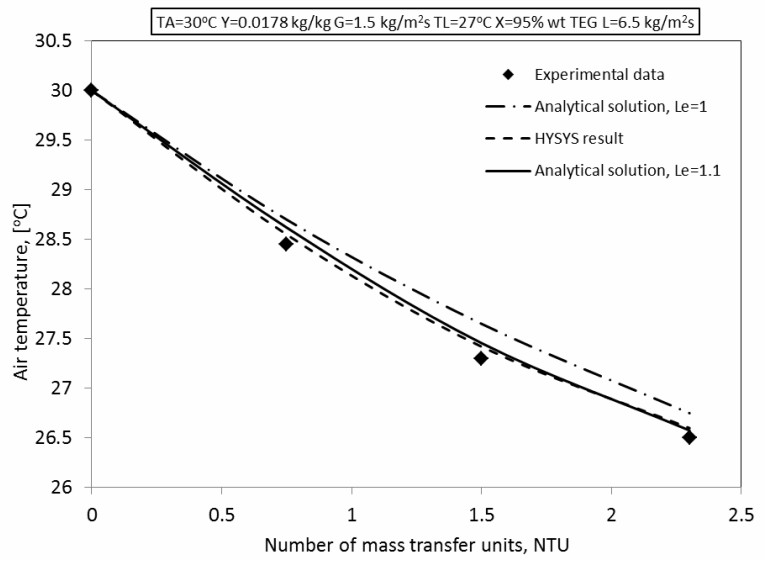

Figure 4: Comparison between the analytical solutions (with $\mathrm{Le}=1 \& \mathrm{Le}=1.1$ ), the experimental data of Zurigat et al. (2004) and HYSYS results for the changes of air temperature in the dehumidifier.

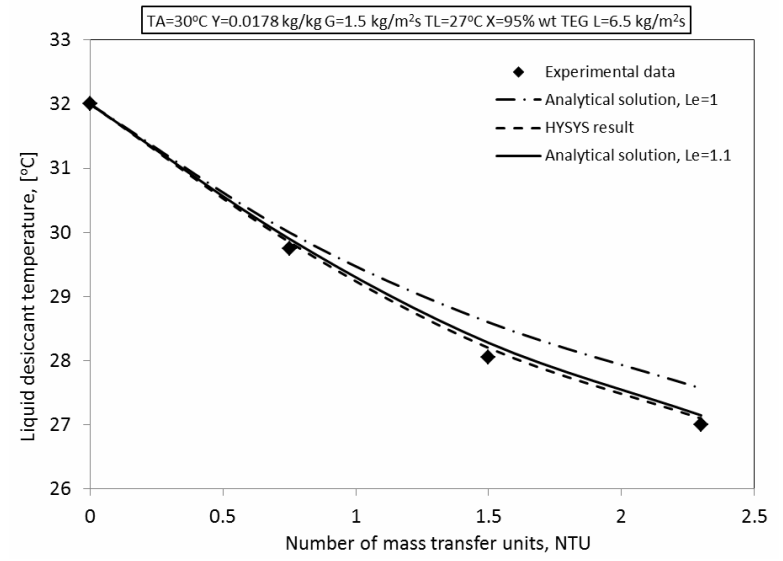

Figure 5: Comparison between the analytical solutions (with $\mathrm{Le}=1 \& \mathrm{Le}=1.1$ ), the experimental data of Zurigat et al. (2004) and HYSYS results for the changes of liquid desiccant temperature in the dehumidifier.

In most of the literature, the Lewis number is assumed to be unity for simplification of the analysis. Stevens (1989) also found a disparity between experimental data and modeled results and gave the explanation of either experimental error or the use of a unit value for the Lewis number. More precise results were obtained with a value of $\mathrm{Le}=1.2$. Chen et al. (2006) also believed that the Lewis number can be different from unity. The authors reported a value of $\mathrm{Le}=1.06$ for the air dehumidification process and $\mathrm{Le}=0.95$ for the liquid desiccant regeneration process. Babakhani (2009) showed that the results of air dehumidification can be improved with $\mathrm{Le}=1.1$ and liquid desiccant regeneration can be improved with $\mathrm{Le}=0.9$. Chengqin et al. (2006) found that the Lewis number varied from one case to another. They reported values for the Lewis number between 0.7 and 1.4 for both the air dehumidification and liquid regeneration processes in order to obtain the optimum results. The authors believed that this might be due to a large variety of complexities, e.g., non-uniformly wetted conditions, fin effects of packing materials, discrete and lumped liquid streams and associated increases in heat/mass transfer resistances in the liquid phase, etc. Therefore, the value of the Lewis number can influence the results obtained from the analytical solution. It is clear that one of the effective variables in the Lewis number as defined is the heat and mass transfer coefficient. Several researchers presented different coefficients for evaluating heat and mass transfer coefficients. Using of these coefficient without considering their accuracy would increase the error in the model. Another reason is probably related to the equilibrium humidity ratio. The change trend of the 
equilibrium humidity ratio is not linear and this strongly nonlinearity can be an error factor. Hence, as the results show, by using HYSYS software we can obtain better prediction than the analytical solution because the software has all of the required physical parameters to estimate the outlet parameters exactly. Especially, the software has thermodynamic relations for estimating the liquid vapour pressure. Thus, it can predict physical properties like vapour pressure without error and leads to an accurate simulation. This solution with $\mathrm{Le}=1.1$ can give every available variable distribution like the traditional numerical solution and can be used for seasonal performance simulations with little computing time. Therefore, one can use the present analytical solution with acceptable confidence. A comparison between this study and the analytical and experimental data of Fumo and Goswami (2002) was carried out, as shown in Figure 6. According to this figure, it is clear that the present study predicts better than analytical solution of Fumo and Goswami. Consequently, we can use the analytical solution derived in this paper to predict with good accuracy the outer operational parameters of an air dehumidifier.

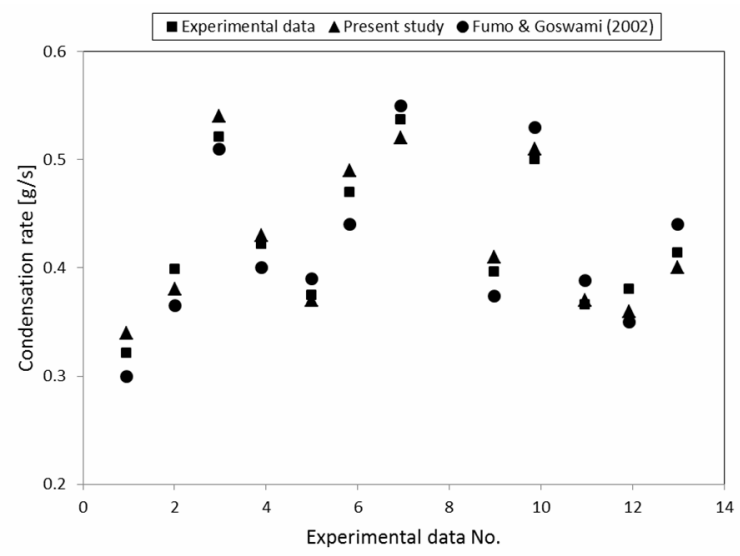

Figure 6: Comparison between the present study and the set of experimental data and analytical solutions of Fumo and Goswami (2002).

\section{CONCLUSION}

An analytical solution of adiabatic heat and mass transfer in a dehumidifier was developed under several reasonable assumptions. The performance predicted by the analytical solution shows very good agreement with the experimental data available in the literature. This solution can give every possible distribution available with the traditional numerical solution and can be used for seasonal performance simulations with very little computing time. It is found that the value of the Lewis number can be different from unity, i.e., in this study, Le $=1.1$ for the air dehumidification. A comparison was made between the results of the present study and the analytical solutions in Chen et al. (2006) and Chengqin et al. (2006). It is clear that the results predicted by the present analytical solution are the most accurate. It is interesting to point out that the major advantages of the present study are the clearly defined parameters and the ease of applying the obtained correlations for the evaluation of the outlet conditions, e.g., outlet air humidity and temperature, and the outlet liquid temperature.

\section{NOMENCLATURE}

\section{Symbols}

\begin{tabular}{|c|c|c|}
\hline$a_{w}$ & $\begin{array}{l}\text { wetted surface area of } \\
\text { packing }\end{array}$ & $\mathrm{m}^{2} / \mathrm{m}^{3}$ \\
\hline$c_{p}$ & specific heat & $\mathrm{kJ} / \mathrm{kg}{ }^{\circ} \mathrm{C}$ \\
\hline$F_{g}$ & $\begin{array}{l}\text { gas phase mass transfer } \\
\text { coefficient }\end{array}$ & $\mathrm{kmol} / \mathrm{m}^{2} \mathrm{~s}$ \\
\hline$G_{s}$ & mass flow rate of dry air & $\mathrm{kg} / \mathrm{s}$ \\
\hline$h_{g}$ & $\begin{array}{l}\text { gas phase heat transfer } \\
\text { coefficient }\end{array}$ & $\mathrm{W} / \mathrm{m}^{2}{ }^{\circ} \mathrm{C}$ \\
\hline $\bar{h}$ & normalized heat of abortion & ${ }^{\circ} \mathrm{C}$ \\
\hline$h_{f g}$ & heat of absorption & $\mathrm{kJ} / \mathrm{kmol}$ \\
\hline Le & $\begin{array}{l}\text { Lewis number, } \\
\text { dimensionless }\end{array}$ & $(-)$ \\
\hline$M$ & $\begin{array}{l}\text { water vapor molar mass to } \\
\text { air molar mass ratio }\end{array}$ & $(-)$ \\
\hline$N T U$ & number of transfer unit & $(-)$ \\
\hline$R$ & $\begin{array}{l}\text { air to solution heat capacity } \\
\text { rate ratio }\end{array}$ & $(-)$ \\
\hline$R_{A}$ & $\begin{array}{l}\text { specific area to effective } \\
\text { interfacial area ratio }\end{array}$ & \\
\hline$R_{H}$ & $\begin{array}{l}\text { air to mixture of air and } \\
\text { water vapor specific heat } \\
\text { capacity ratio }\end{array}$ & $(-)$ \\
\hline$T$ & temperature & ${ }^{\circ} \mathrm{C}$ \\
\hline$Y$ & air humidity ratio & $\begin{array}{r}\text { kg water vapor/ } \\
\text { kg dry air }\end{array}$ \\
\hline & column height & \\
\hline
\end{tabular}

\section{Greek Letters}

$\lambda_{0} \quad$ latent heat of condensation $(\mathrm{kJ} / \mathrm{kg})$

\section{Subscripts}

a air 


$\begin{array}{ll}e & \text { equilibrium condition } \\ l & \text { liquid desiccant } \\ m & \text { average } \\ v & \text { Water vapour }\end{array}$

\section{REFERENCES}

Chengqin, R., Jiang, Y. and Yianpin, Z., Simplified analysis of coupled heat and mass transfer processes in packed bed liquid desiccant-air contact system. Sol. Energy, 80, 121-131 (2006).

Chen, X. Y., Li, Z., Jiang, Y. and Qu, K. Y., Analytical solution of adiabatic heat and mass transfer process in packed-type liquid desiccant equipment and its application. Sol. Energy, 80, 1509-1516 (2006).

Babakhani, D., Developing an application analytical solution of adiabatic heat and mass transfer processes in a liquid desiccant dehumidifier/ regenerator. Chem. Eng. Tech., 32, 1875-1884 (2009).

Factor, H. M. and Grossman, G., A packed bed dehumidifier/regenerator for solar air conditioning with liquid desiccants. Sol. Energy, 24, 541550 (1980).

Fumo, N. and Goswami, D. Y., Study of an aqueous lithium chloride desiccant system: Air dehumidification and desiccant regeneration. Sol. Energy, 72, 351-361 (2002).

Gandhidasan, P., A simplified model for air dehumidification with liquid desiccant. Sol. Energy, 76, 409-416 (2004).

Hellmann, H. M. and Grossman, G., Investigation of an open-cycle dehumidifier-evaporator-regenerator (DER) absorption chiller for low grade heat utilization. ASHRAE Trans., 101, 1281-1289 (1995a).

Hellmann, H. M. and Grossman, G., Simulation and analysis of an open cycle dehumidifierevaporator-regenerator (DER) absorption chiller for low-grade heat utilization. Int. J. Refrig., 18, 177-189 (1995b).
Jain, S., Dhar, P. L., and Kaushik, S. C., Experimental studies on the dehumidifier and regenerator of a liquid desiccant cooling system. Appl. Thermal Eng., 20, 253-267 (2000).

Khan, A. Y. and Martinez, J. L., Modeling and parametric analysis of heat and mass transfer of a hybrid liquid desiccant absorber. Energy Convers. Manage., 39, 1095-1112 (1998).

Kessling, W., Laevemann, E. and Kapfhammer, C., Energy storage for desiccant cooling systems component development. Sol. Energy, 64, 209221 (1998a).

Kessling, W., Laevemann, E. and Peltzer, M., Energy storage in open cycle liquid desiccant cooling systems. Int. J. Refrig., 21, 150-156 (1998b).

Liu, X., Jiang, Y., Xia, J. and Chang, X., Analytical solutions of coupled heat and mass transfer processes in liquid desiccant air dehumidifier/ regenerator. Energy Convers. Manage., 48, 22212232 (2007).

Longo, G. A. and Gasparella, A., Experimental and theoretical analysis of heat and mass transfer in a packed column dehumidifier/regenerator with liquid desiccant. Int. J. Heat and Mass Transfer, 48, 5240-5254 (2005).

Saman, W. Y. and Alizadeh, S., Modeling and performance analysis of a cross-flow type plate heat exchanger for dehumidification/cooling. Sol. Energy, 70, 361-372 (2001).

Scalabrin, G. and Scaltriti, G., A liquid sorptiondesorption system for air conditioning with heat at lower temperature. J. Sol. Energy Eng., 112, 70-75 (1990).

Stevens, D. I., An effectiveness model of liquid desiccant system heat/mass exchangers. Sol. Energy, 42, 449-455 (1989).

Treybal, R., Mass Transfer Operations. 3rd Ed., McGraw-Hill, New York (1980).

Zurigat, Y. H., Abu-Arabi, M. K. and Abdul-wahab, S. A., Air dehumidification by triethylene glycol desiccant in a packed column. Energy Convers. Manage., 45, 141-155 (2004). 